\title{
Review \\ Role of Pretransplant Treatments for Patients with Hepatocellular Carcinoma Waiting for Liver Transplantation
}

\author{
Kohei Ogawa * (D) and Yasutsugu Takada (D) \\ Department of HBP and Breast Surgery, Ehime University, Shitsukawa, Toon 791-0295, Ehime, Japan; \\ takaday@m.ehime-u.ac.jp \\ * Correspondence: ogawa.kohei.vz@ehime-u.ac.jp; Tel.: +81-89-960-5327
}

check for

updates

Citation: Ogawa, K.; Takada, Y. Role of Pretransplant Treatments for Patients with Hepatocellular Carcinoma Waiting for Liver Transplantation. Cancers 2022, 14, 396. https://doi.org/10.3390/

cancers14020396

Academic Editor:

George Papatheodoridis

Received: 29 November 2021

Accepted: 12 January 2022

Published: 13 January 2022

Publisher's Note: MDPI stays neutral with regard to jurisdictional claims in published maps and institutional affiliations.

Copyright: (C) 2022 by the authors. Licensee MDPI, Basel, Switzerland. This article is an open access article distributed under the terms and conditions of the Creative Commons Attribution (CC BY) license (https:// creativecommons.org/licenses/by/ $4.0 /)$.

\begin{abstract}
Simple Summary: Hepatocellular carcinoma (HCC) is the fifth most common cancer in men worldwide and the second leading cause of cancer death. Liver transplantation (LT) is one of the treatment options for patients with HCC. Recently, there have been many reports of the usefulness of locoregional therapy, such as transarterial chemoembolization and radiofrequency ablation, for HCC as pretreatment before LT. In Western countries, locoregional therapy is used to bridge until transplantation to prevent drop-outs from the waiting list or for downstaging to treat patients with advanced HCC who initially exceed the criteria for LT. With the progress of locoregional therapy, new reports on the effects of bridging and downstaging locoregional therapy as pretransplant treatment are increasing in number.
\end{abstract}

\begin{abstract}
Recently, there have been many reports of the usefulness of locoregional therapy such as transarterial chemoembolization and radiofrequency ablation for hepatocellular carcinoma (HCC) as pretreatment before liver transplantation (LT). Locoregional therapy is performed with curative intent in Japan, where living donor LT constitutes the majority of LT due to the critical shortage of deceased donors. However, in Western countries, where deceased donor LT is the main procedure, LT is indicated for early-stage HCC regardless of liver functional reserve, and locoregional therapy is used for bridging until transplantation to prevent drop-outs from the waiting list or for downstaging to treat patients with advanced HCC who initially exceed the criteria for LT. There are many reports of the effect of bridging and downstaging locoregional therapy before LT, and its indications and efficacy are becoming clear. Responses to locoregional therapy, such as changes in tumor markers, the avidity of FDG-PET, etc., are considered useful for successful bridging and downstaging. In this review, the effects of bridging and downstaging locoregional therapy as a pretransplant treatment on the results of transplantation are clarified, focusing on recent reports.
\end{abstract}

Keywords: liver transplantation; hepatocellular carcinoma; bridging; downstaging; locoregional therapy

\section{Introduction}

As of 2018, hepatocellular carcinoma (HCC) is the fifth most common cancer in men worldwide and the second leading cause of cancer death [1]. Liver transplantation (LT) is one of the treatment options in patients with HCC. Since LT can treat not only HCC, but also underlying liver cirrhosis, it is an ideal treatment method for patients with decompensated cirrhosis with HCC who cannot be treated with treatments other than LT. In Europe and the United States (USA), LT is indicated for early-stage HCC regardless of liver functional reserve. In Japan, where there are few deceased donors available, however, locoregional treatment such as liver resection, transarterial chemoembolization (TACE), and radiofrequency ablation (RFA) is indicated while liver functional reserve is good, and LT is selected when liver functional reserve becomes poor, and there is no treatment option other than LT. Therefore, in Europe and the USA, the purpose of pretransplant locoregional therapy is for bridging to LT, preventing patients with early-stage HCC from dropping 
out of the waiting list, or for downstaging intermediate stage HCC to put the patients on the waiting list. On the other hand, in Japan, locoregional therapy is often given for the purpose of radical cure, and salvage LT is indicated for patients whose liver functional reserve deteriorates gradually with repeated locoregional therapies.

In patients with early-stage HCC, locoregional therapy may shrink the tumor and provide better transplant outcomes, while repeated locoregional therapies may advance HCC, which might result in worsening post-transplant outcomes. On the other hand, in patients with advanced HCC, if downstaging to within the indication criteria for LT is performed successfully by locoregional therapy, the results after LT might be close to those of patients within the indication criteria initially.

This review focuses on the recent literature and clarifies the role of locoregional therapy before LT.

\section{Indications for Liver Transplantation in Patients with Hepatocellular Carcinoma}

In the history of deceased donor LT (DDLT) in Europe and the USA, LT has been performed as a treatment method for unresectable HCC from the early period. However, the results of LT for HCC were dismal until the early 1990s. O'Grady et al. [2] reported that the 2-year survival rate after LT for HCC was $40 \%$ or less, and $65 \%$ of cases that survived more than 3 months after LT recurred. Ringe et al. [3] reported that the 5-year survival rate was less than $20 \%$. Due to the high recurrence rate, LT for patients with HCC using limited organs has been controversial. On the other hand, as a promising result, Iwatsuki et al. compared the results of LT to hepatectomy according to the TNM classification and reported that the 5-year survival rate of LT in Stage II was 68\%, which was significantly better than the $43 \%$ of hepatectomy [4]. Furthermore, in 1993, Bismuth et al. [5] reported a 3-year recurrence-free survival rate of $83 \%$ after LT in cases with 1-2 lesions $\leq 3 \mathrm{~cm}$, which was significantly better than that of $44 \%$ in cases with $\geq 3$ lesions $\geq 3 \mathrm{~cm}$ and that of $18 \%$ after hepatectomy. They showed that tumor size and number affected transplant outcomes, as well as the superiority of LT over hepatectomy. Then, in 1996, Mazzaferro et al. [6] reported that the 4-year survival rate after LT of single HCC $\leq 5 \mathrm{~cm}$ or 1-3 lesions $\leq 3 \mathrm{~cm}$ was $85 \%$ (4-year recurrence-free survival rate $92 \%$ ). Since then, these Milan criteria (single lesion $\leq 5 \mathrm{~cm}$ or $1-3$ lesions $\leq 3 \mathrm{~cm}$ ) have been used worldwide as indication criteria for DDLT.

Currently, according to the European Association for the Study of the Liver (EASL) clinical practice guideline, HCC within the Milan criteria is divided into very early stage (single, $\leq 2 \mathrm{~cm}$ ) and early stage (single $\geq 2 \mathrm{~cm}, \leq 5 \mathrm{~cm}$, or $2-3$ lesions $\leq 3 \mathrm{~cm}$ ). If liver function is good, ablation or resection is recommended for HCC in the very early stage, and LT is indicated for patients with HCC in the early stage, for whom liver resection is unsuitable due to portal hypertension [7].

In the USA, organ transplantation is regulated by the United Network for Organ Sharing (UNOS), and HCC patients with decompensated cirrhosis are prioritized by the Model for End-stage Liver Disease (MELD) score. On the other hand, patients with compensatory cirrhosis have a low MELD score, and they do not get to LT by the MELD score. Therefore, priority is determined according to the number and size of HCC and the registration period. HCC within the Milan criteria is divided into stage T1 (EASL very early stage) and stage T2 (EASL early stage), and patients with T2 HCC are prioritized. Since 2005, T2 patients have been given a MELD-Na score of 22 points, and 3 points have been added every 3 months [8]. However, in 2015, the system was revised so that T2 patients are not given the exceptional MELD-Na score until a 6-month mandatory period after enrollment, and a MELD-Na score of 28 points is given after 6 months if the tumor meets the Milan criteria with alpha-fetoprotein (AFP) below a certain level [9]. On the other hand, in Japan, LT is indicated for patients with HCC within the Milan criteria or 5-5-500 criteria (1-5 lesions $\leq 5 \mathrm{~cm}$, AFP $\leq 500 \mathrm{ng} / \mathrm{mL}$ ) with Child-Pugh classification C liver cirrhosis [10]. The priority goes up with a worsening MELD score. For patients with low MELD scores, however, a MELD score of 16 points is given, and 2 points are added every 3 months if 
HCC meets the criteria. Using this allocation system, even in the USA, where the number of deceased donors is overwhelmingly larger than in Japan, it has been reported that $12 \%$ of HCC patients on the waiting list drop-out due to HCC progression in 6 months and 15-30\% in a year, and the waiting period is often prolonged more than one year [11,12]. Therefore, in order to get to LT, it is necessary to wait while controlling the progression of HCC.

On the other hand, in living-donor liver transplantation (LDLT), which is not affected by the allocation system, the Milan criteria are considered to be too strict. Therefore, expanded criteria with higher number and size, as well as biological surrogates, such as AFP, des-gamma-carboxyprothrombin (DCP), FDG-PET, and response to pretransplant locoregional therapy, have been reported with results to comparable the Milan criteria [10,13-18]. In recent years, models for predicting the recurrence rate of HCC after LT with more accuracy, using various parameters including tumor size, number, and AFP etc., have been reported [19-22]. Among them, the formula by Ivanics et al. from Toronto, in which many parameters were analyzed using machine learning, a type of artificial intelligence, has been reported to be more accurate than the AFP score and the Model of Recurrence After Liver Transplant (MORAL) score [22].

As morphological data that determine the indication for LT, classical HCC, which shows enhanced staining in the arterial phase and wash-out in the delayed phase on dynamic CT, has been the target at many facilities so far. With recent advances in diagnostic imaging, however, the American College of Radiology proposed the Liver Imaging Reporting and Data System (LI-RADS) in 2011 with the aim of making diagnostic imaging of HCC more universal and more accurate [23]. In the LI-RADS, liver nodules are classified into 5 subclasses: LR-1 (benign), LR-2 (probably benign), LR-3 (boundary lesion), LR-4 (probably HCC), and LR-5 (HCC). It has been reported that the HCC-specific diagnostic accuracy is $37 \%$ for LR-3 and 95\% for LR-5 [24,25]. Although LT is indicated for tumors classified as LR-5, the impact of LR-3 and LR-4 tumors on LT results has not been clarified so far.

Recently, Mazzaferro et al. [26] have released metroticket 2.0, an online calculator with tumor diameter, total number, and AFP as parameters, which is useful to predict recurrence rates in individual cases accurately. Centonze et al. [27] from Italy investigated the oncological impact of the LI-RADS classification using this metroticket 2.0. They reported that excluding LR-3 and LR-4 nodules resulted in a significant drop in its accuracy. In the future, it is expected that a more accurate recurrence prediction model will be developed by using these more accurate morphological data.

\section{Bridging Therapy to Liver Transplantation}

\subsection{Is It Meaningful to Perform Bridging Therapy?}

To date, there is controversy regarding performing locoregional bridging therapy (BT) for patients waiting for LT. However, due to the allocation system, the patient will be dropped off the waiting list if the HCC progresses and does not meet the transplant indication criteria. In order to perform LT, it is necessary to keep the HCC stage within the transplant indication criteria. Therefore, TACE and RFA are performed as BT in many facilities. In addition to preventing drop-out from the waiting list mentioned above, BT has the potential to shrink tumors and improve the results of LT and exclude biologically aggressive HCC.

\subsection{When to Perform Bridging Therapy?}

In 1999, Llovet et al. [28] reported that the drop-out rate within 6 months was $23 \%$ without BT. After that, Ashoori et al. [29] reported that the drop-out rates at 6 months and 12 months were $2.8 \%$ and 5.5\%, respectively, with RFA and TACE. Habibollahi et al. [30] reported good results of LT by following patients with T1 HCC without BT and performing BT when the waiting period was extended by another 6 months at the time when HCC progressed to T2. Mehta et al. [31] also reported that T1 tumors were followed up every 3 months, and less than $10 \%$ of them progressed beyond T2, which is outside the Milan criteria. For the LT candidate, they recommended that it is better to monitor the progress 
of the $\mathrm{T} 1$ tumor without $\mathrm{BT}$, but once the AFP is elevated to $\geq 500 \mathrm{ng} / \mathrm{mL}$ or the tumor is growing in a short period of time, locoregional therapy should be given as soon as possible. Lai et al. [32] reported that when transplant failure was defined as drop-out from the preoperative waiting list or postoperative recurrence in patients within the Milan criteria, one BT reduced transplant failure by $49 \%$, and up to 3 BTs reduced it by $34 \%$. However, the benefits of bridging disappear with four or more BTs. On the other hand, Tan et al. [33] from Singapore reported that there was no difference in the frequency of drop-outs from the waiting list between the BT group and the non-BT group, but the waiting period tended to be longer in the BT group. They concluded that BT might enable the LT candidate with HCC to wait longer. Although there has been no prospective, randomized, controlled trial to date, there is consensus that locoregional therapy for HCC should be given if the waiting period is 6 months or longer to prevent waiting list drop-out during the waiting period. $[34,35]$.

\subsection{Effect of Bridging Therapy on Hepatocellular Carcinoma Recurrence after Liver Transplantation}

Regarding the relationship between BT and recurrence of HCC after LT, there are many reports showing that there was no difference in LT results between the BT group and the non-BT group for HCC within the Milan criteria, and BT was not effective for HCC within the Milan criteria [36,37]. In a multicenter study in the USA, the 1, 3, and 5 -year survival rates of 747 patients without locoregional therapy and 2854 patients with locoregional therapy were $89 \%, 77 \%$, and $68 \%$ vs. $85 \%, 75 \%$, and $68 \%$, respectively $(p=0.490)$, and the 5 -year recurrence rate was $11.2 \%$ vs. $10.1 \%(p=0.474)$, showing no significant differences [38]. In addition, there is a report from South Korea that, when the tumor stage was T1 or T2 (within the Milan criteria), there was no significant difference in the recurrence rate between the BT group and the non-BT group [39]. On the other hand, Oligane et al. [40] reported that the overall survival rate was higher, and the recurrence rate was lower in the BT group with T2 tumors that received MELD exceptions in a study using the UNOS database in the USA. Renner et al. [41] from Germany reported that patients whose HCC progressed from within the Milan to outside the Milan criteria despite BT had lower overall survival and recurrence-free survival than those controlled within the Milan criteria. On the other hand, Ogawa et al. [42] from Kyoto, Japan, reported that if LT was performed within the Kyoto criteria ( $\leq 10$ lesions $\leq 5 \mathrm{~cm}, \mathrm{DCP} \leq 400 \mathrm{mAU} / \mathrm{mL}$ ), results of LT were relatively good. They concluded that it was useful to keep the HCC stage within the expanded criteria by BT for the recurrence of HCC after LT even if it exceeds the Milan criteria. Extended criteria incorporating DCP have been reported mainly from Asian countries, including Japan $[15,16]$, and a recent meta-analysis showed that the frequency of HCC recurrence was 5 times higher in cases with a high level of DCP at LT [43].

It has been reported that when locoregional therapy was effective enough to render the tumor completely necrotic, the results after LT were good [44-46]. However, imaging examinations often overestimate the therapeutic effect compared to histopathological findings [47-50]. Rubinstein et al. [51] reported that $77 \%$ of patients had viable tumors even though imaging examinations showed complete response (CR). On the other hand, $\mathrm{Xu}$ et al. [46] reported that partially necrotic HCC induced by locoregional therapy was associated with an increased risk of lymphatic metastases. Lai et al. [32] reported that patients who show a poor response to locoregional therapy have a predictably greater risk for pretransplant tumor-related delisting or posttransplant recurrence. Therefore, if the effect of locoregional therapy is insufficient, the risk of recurrence of HCC might increase. Table 1 summarizes the results of BT in selected studies in the past 5 years $[33,38,39,52-55]$. 
Table 1. Results of bridging locoregional therapies for HCC before LT in selected studies of the past 5 years.

\begin{tabular}{|c|c|c|c|c|c|c|c|c|}
\hline Author & Country & Year & $\begin{array}{l}\text { No. of } \\
\text { Patients }\end{array}$ & $\begin{array}{l}\text { Selection } \\
\text { Criteria }\end{array}$ & $\begin{array}{c}\text { Time } \\
\text { Period on } \\
\text { Waitlist to } \\
\text { LT }\end{array}$ & $\begin{array}{l}\text { Treatment } \\
\text { Modality }\end{array}$ & $\begin{array}{l}\text { Drop-out } \\
\text { Rate }\end{array}$ & $\begin{array}{l}\text { OS, RR, DFS, and } \\
\text { RFS after LT }\end{array}$ \\
\hline Lee [52] & USA & 2017 & 121 & $\begin{array}{l}\text { MC (within } \\
\text { MC 90.1\%) }\end{array}$ & $\begin{array}{c}10.2 \\
\text { months }\end{array}$ & RFA & $\begin{array}{c}1-\mathrm{y} 13.5 \%, 3-\mathrm{y} \\
37.2 \%, 5-\mathrm{y} \\
58.1 \%\end{array}$ & $\begin{array}{l}\text { RR 1-y 2.5\%, 3-y } \\
5.3 \%, 5-y 7.2 \%\end{array}$ \\
\hline Tan [33] & Singapore & 2018 & 36 & $\mathrm{MC}$ & $\begin{array}{c}291 \\
(17-844) \\
\text { days }\end{array}$ & TACE, RFA & $\begin{array}{l}\text { 6-m } 18.7 \% \\
1-y 33.3 \%\end{array}$ & 3-y DFS 71\% \\
\hline Lee [39] & Korea & 2020 & $\begin{array}{l}\text { T1 } 91 \\
\text { T2 } 54\end{array}$ & $\begin{array}{l}\text { OPTN T1, } \\
\text { T2 }\end{array}$ & NA & $\begin{array}{c}\text { TACE, RFA, } \\
\text { RT, } \\
\text { Resection }\end{array}$ & NA & $\begin{array}{c}\text { RFS } \\
\text { T1 1-y 97.8\%, 3-y } \\
96.5 \%, 5-y=94 \% \\
\text { T2 1-y 94.8\%, 3-y } \\
92.1 \%, 90.7 \%\end{array}$ \\
\hline $\mathrm{Na}$ [53] & Korea & 2016 & 53 & $\mathrm{MC}$ & NA & $\begin{array}{c}\text { TACE, RFA, } \\
\text { PEI }\end{array}$ & $\begin{array}{c}\text { Within } \\
\rightarrow \text { Beyond } \\
24.5 \%\end{array}$ & $\begin{array}{c}\text { RFS 3-y 78.3\%, 5-y } \\
73.1 \%\end{array}$ \\
\hline Affonso [54] & Brazil & 2019 & 136 & $\mathrm{MC}$ & $\begin{array}{c}6.6 \\
(0.60-30.47) \\
\text { months }\end{array}$ & DEB-TACE & $33.8 \%$ & $\begin{array}{c}\text { RFS 3-y 76.5\%, 5-y } \\
72.3 \%\end{array}$ \\
\hline Xing [55] & USA & 2017 & 155 & $\mathrm{MC}$ & $\begin{array}{c}5.92 \\
(0.12-67.33) \\
\text { months }\end{array}$ & $\begin{array}{c}\text { TAE, TACE, } \\
\text { DEB-TACE, } \\
\text { RE, RFA }\end{array}$ & $28.3 \%$ & $\begin{array}{c}\text { OS 3-y 85\%, 5-y } \\
72 \%\end{array}$ \\
\hline Agopian [38] & USA & 2017 & 2854 & $\mathrm{MC}$ & NA & $\begin{array}{l}\text { TACE, RE, } \\
\text { RFA, PEI, } \\
\text { Resection, } \\
\text { MW, etc. }\end{array}$ & NA & $\begin{array}{c}\text { RFS 1-y 89\%, 3-y } \\
77 \%, 5-y 68 \%\end{array}$ \\
\hline
\end{tabular}

OS: Overall survival; RR: Recurrence rate; DFS: Disease-free survival; RFS: Recurrence-free survival; LT: Liver transplantation; MC: Milan criteria; RFA: Radiofrequency ablation; TACE: Transarterial chemoembolization; RT: Radiation therapy; OPTN: Organ procurement and transplantation network; NA: Not available; PEI: Percutaneous ethanol injection; DEB: Drug-eluting beads; RE: Radioembolization; MW: Microwave ablation.

\section{Downstaging of Hepatocellular Carcinoma for Liver Transplantation}

\subsection{Downstaging from Outside the Milan Criteria to within the Milan Criteria}

Downstaging is performed for the purpose of reducing tumor volume to within the LT indication criteria for patients whose HCC stage is outside the LT indication criteria. Downstaging HCC to within the LT indication criteria (morphological downstaging) is a means for performing LT, but its true purpose is to reduce the risk of recurrence after LT (biological downstaging) by selecting HCCs with low biological aggressiveness that have few recurrences after LT [56]. Since the allocation criteria in many countries were based on the Milan criteria, there are many reports of downstaging from outside the Milan criteria to within the Milan criteria. Total tumor volume (TTV), AFP, etc., have been reported as predictors for successful downstaging from outside the Milan criteria to within the Milan criteria [57,58]. Murali et al. [59] reported that cases with TTV $<200 \mathrm{~cm}^{3}$ were successfully downstaged. Regarding AFP, Bova et al. reported that AFP $<100 \mathrm{ng} / \mathrm{mL}$ after locoregional therapy was a predictor of successful downstaging, and Yao et al. [60] reported that AFP > $1000 \mathrm{ng} / \mathrm{mL}$ before treatment was a negative factor for downstaging. It has been reported that the results of LT for patients who succeeded in downstaging within the Milan criteria by locoregional therapy were almost the same as when LT was performed for patients within the Milan criteria in both DDLT and LDLT settings [53,60-63]. On the other hand, there are some reports of a higher recurrence rate after LT in downstaged cases from outside to within the Milan criteria. Ravaioli et al. [64] from Italy reported that the recurrence rate 
was $7.6 \%$ for those who remained within the Milan criteria, $20.9 \%$ for those who were downstaged to the Milan criteria, 31.6\% for those who failed downstaging, and 30.4\% for those who did not downstage, when the upper limit of the tumor was $\leq 8 \mathrm{~cm}$ for single lesion, $\leq 5 \mathrm{~cm}$ for bifocal lesions, and $\leq 5$ lesions with the maximum diameter of $4 \mathrm{~cm}$ with the total tumor diameter $\leq 12 \mathrm{~cm}$. They also reported that pathological findings showed that the frequency of microvascular invasion and moderate to poorly differentiated HCC was higher in cases with downstaging than in cases originally within the Milan criteria. Affonso et al. [54] from Brazil reported that there were more post-transplant recurrences in downstaging cases from outside to within the Milan criteria compared to bridging cases within the Milan criteria (25\% vs. 5.81\%, $p=0.020)$. The possible cause of a higher recurrence rate in downstaging cases from outside to within the Milan criteria might be the dissociation of imaging and histopathological findings. Kim et al. [65] reported that the results of LT for cases showing pathological downstaging to T2 (within the Milan criteria) were the same as those within the Milan criteria, whereas the results of LT were poor for cases that were not pathologically downstaged. They listed one or less viable tumors on imaging, viable tumor diameter of $\leq 1 \mathrm{~cm}$, and AFP $\leq 20 \mathrm{ng} / \mathrm{mL}$ as independent predictors for successful pathological downstaging.

\subsection{Is Downstaging Necessary for Patients Outside the Milan Criteria but within the Expansion Criteria?}

The expansion criteria proposed at each transplant institute often incorporate biomarkers in addition to HCC morphology, and LT results using these expansion criteria are reported to be equivalent to those within the Milan criteria. However, most of them include patients within the Milan criteria, and the recurrence rate after LT is reported to be slightly higher in patients within the expansion criteria but outside the Milan criteria than in patients within the Milan criteria. Kamo et al. [66] reported a 5-year recurrence rate of $22 \%$ when LT was performed in patients with intermediate-stage HCC within the Kyoto criteria. This recurrence rate was significantly lower than the $66 \% 5$-year recurrence rate in patients with intermediate-stage HCC outside the Kyoto criteria, but higher than their previous 5-year recurrence rate of 5\% in patients within the Milan criteria [67]. In addition, Shimamura et al. [10], who examined the 5-5-500 criteria, showed no significant difference between the Milan criteria and the 5-5-500 criteria for recurrence-free survival, but subgroup analysis showed that patients within both the Milan criteria and 5-5-500 did significantly better than patients outside the Milan criteria but within the $5-5-500$ criteria. From these data, it seems that it is meaningful to downstage patients with intermediate HCC to within the Milan criteria by preoperative locoregional therapy, even patients with HCC within the expanded criteria, in order to reduce the risk of recurrence after LT.

\subsection{Comparison of Liver Transplantation after Downstaging with Other Treatments}

There was a randomized, controlled trial conducted by Mazzaferro et al. [68] to examine whether LT after downstaging was superior to other treatments for patients with good liver reserve. They randomly divided patients with successful downstaging into an LT group and a control group that was treated with non-transplant therapy when recurrence occurred. They reported that the LT group did better than the control group in both overall survival and tumor event-free survival. On the other hand, regarding the necessity for LT when complete radical treatment is performed by locoregional therapy, Vitale et al. [56] reported comparable results in cases in which complete biological downstaging could be achieved and maintained by strong locoregional therapy to those in the LT group. They concluded that their data strongly support the current allocation system in Italy in which there is no priority in cases obtaining CR by downstaging.

\subsection{What Is the Upper Limit of Tumor Burden for Downstaging?}

In many past reports, although the stage of HCC before downstaging was outside the Milan criteria, most of the cases met the expansion criteria of each institution and the 
upper limit of tumor burden for downstaging that allows a low recurrence rate after LT was not clear. Shinha et al. reported that, among patients with HCC within the University of California at San Francisco (UCSF) criteria, 82.4\% could be downstaged to the Milan criteria, which was significantly higher than the $64.8 \%$ of patients with HCC outside the UCSF criteria [69]. They also reported that recurrence was observed in 3 of 10 cases that were originally outside the UCSF criteria even after downstaging to the Milan criteria. In a study using the UNOS database in the USA, Mehta et al. [70] compared recurrence rates among 3 groups: patients within the Milan criteria; patients who were successfully downstaged to within the Milan criteria from the UNOS downstaging inclusion criteria (single lesion of 5 to $8 \mathrm{~cm}$, or up to 3 lesions of 3 to $5 \mathrm{~cm}$ with the sum of tumor diameter $\leq 8 \mathrm{~cm}$, or 4 to 5 lesions with the sum of tumor diameter $\leq 8 \mathrm{~cm}$ ); and patients who were successfully downstaged to within the Milan criteria from outside the UNOS downstaging criteria. The 3-year recurrence rates were significantly lower in patients within the Milan criteria group (6.9\% vs. $12.8 \%$ vs. $16.7 \%$, respectively), but there was no significant difference in the 3-year survival rates between the Milan criteria group and the UNOS downstaging group $(83.2 \%$ vs. $79.1 \%$ vs. $71.4 \%$, respectively). They suggested that the dissociation of preoperative imaging and histopathological findings might be the cause of the higher recurrence rate in the UNOS DS group than in the Milan criteria group. Wu et al. [71] from Taiwan reported that the recurrence rate after LDLT was significantly higher in cases that exceeded the UCSF criteria even with downstaging compared to the cases with or without locoregional therapy within the UCSF criteria. Toso et al. [72] from Switzerland reported that, although the recurrence rate was slightly higher in the downstaging group, there was no difference in survival between the downstaging group and the control group (patients who remained inside the LT criteria) when the tumor burden was limited to TTV $\leq 115 \mathrm{~cm}^{3}$ and AFP $\leq 400 \mathrm{ng} / \mathrm{mL}$. From these reports, if HCC was pathologically downstaged to within the Milan criteria, the recurrence rate was equivalent to that of the cases within the Milan criteria. However, since dissociation between the imaging findings and the histopathological findings seems to increase with the progress of HCC, it seems reasonable to limit the upper limit of tumor burden for downstaging to cases within the expansion criteria of each institution. On the other hand, in recent years, there have been increasing reports of LT for patients with advanced HCC with portal vein tumor thrombus (PVTT), and among them, Soin et al. [73] from India reported that the transplant results were acceptable in cases with PVTT that were successfully downstaged. In the future, the upper limit of tumors that can be biologically downstaged may be expanded with the progress of preoperative locoregional therapy. Table 2 summarizes the results of downstaging in selected studies of the past 5 years [58,62-64,70,72]. 
Table 2. Results of LT after downstaging of advanced HCC in selected studies of the past 5 years.

\begin{tabular}{|c|c|c|c|c|c|c|c|c|}
\hline Authors & Country & Year & $\begin{array}{l}\text { No. of } \\
\text { Patients }\end{array}$ & $\begin{array}{l}\text { Downstaging } \\
\text { Criteria }\end{array}$ & $\begin{array}{l}\text { Eligibility } \\
\text { Criteria }\end{array}$ & $\begin{array}{l}\text { Treatment } \\
\text { Modality }\end{array}$ & $\begin{array}{l}\text { Successful } \\
\text { DS rate }\end{array}$ & $\begin{array}{c}\text { OS, RR, } \\
\text { DFS, and } \\
\text { RFS after LT }\end{array}$ \\
\hline Chapman [63] & USA & 2017 & $\begin{array}{l}210 \text { (Within } \\
\text { UCSF 35, } \\
\text { Beyond } \\
\text { UCSF 175) }\end{array}$ & $\mathrm{MC}$ & $\begin{array}{c}\text { No } \\
\text { extrahepatic } \\
\text { lesions }\end{array}$ & $\begin{array}{l}\text { TACE, RE, } \\
\text { RFA }\end{array}$ & $42.4 \%$ & $\begin{array}{c}\text { RR Beyond } \\
\text { UCSF 8.9\%, } \\
\text { within UCSF } \\
5.6 \%\end{array}$ \\
\hline Mehta [58] & USA & 2018 & 187 & $\mathrm{MC}$ & $\begin{array}{l}\text { UNOS DS } \\
\text { inclusion } \\
\text { criteria }\end{array}$ & TACE, RFA & $83.4 \%$ & RR $10.1 \%$ \\
\hline Massarollo [62] & Brazil & 2016 & 85 & $\mathrm{MC}$ & $\begin{array}{c}\text { No } \\
\text { extrahepatic } \\
\text { lesions, no } \\
\text { major vascular } \\
\text { invasion }\end{array}$ & TACE & NA & $\begin{array}{c}\text { OS 3-y } 72.0 \% \\
5-y 66.1 \%\end{array}$ \\
\hline Mehta [70] & USA & 2020 & $\begin{array}{l}543 \text { (Within } \\
\text { UNOS DS } \\
\text { criteria 422, } \\
\text { AC 121) }\end{array}$ & $\mathrm{MC}$ & No limitations & NA & NA & $\begin{array}{c}\text { OS within } \\
\text { UNOS DS 3-y } \\
79.1 \%, \text { AC } \\
71.4 \% \\
\text { RR within } \\
\text { UNOS DS } \\
9.2 \%, \text { AC } \\
10.7 \%\end{array}$ \\
\hline Toso [72] & Switzerland & 2019 & 29 & $\begin{array}{c}\text { TTV } \\
115 / \text { AFP } \\
400\end{array}$ & $\begin{array}{l}\text { No limit for } \\
\text { size nor AFP }\end{array}$ & $\begin{array}{l}\text { TACE, RFA, } \\
\text { PEI, } \\
\text { Resection, } \\
\text { etc. }\end{array}$ & NA & DFS 5-y 74\% \\
\hline Ravaioli [64] & Italy & 2019 & 122 & $\mathrm{MC}$ & $\begin{array}{c}\text { Single } \leq 8 \mathrm{~cm}, \\
\text { bifocal } \leq 5 \mathrm{~cm}, \\
\text { multiple } \leq 5 \\
\text { lesions } \leq 4 \mathrm{~cm} \\
\text { each with total } \\
\text { tumor } \\
\text { diameter } \\
\leq 12 \mathrm{~cm}\end{array}$ & $\begin{array}{c}\text { TACE, RFA, } \\
\text { Resection, } \\
\text { PEI }\end{array}$ & $68.4 \%$ & $\begin{array}{c}\text { OS 5-y 63\% } \\
\text { RR 5-y 20.9\% }\end{array}$ \\
\hline
\end{tabular}

OS: Overall survival; RR: Recurrence rate; DFS: Disease-free survival; RFS: Recurrence-free survival; LT: Liver transplantation; UCSF: University of California San Francisco; MC: Milan criteria; TACE: Transarterial chemoembolization; RE: Radioembolization; RFA: Radiofrequency ablation; NA: Not available; UNOS: United Network for Organ Sharing; DS: Downstaging; AC: All comers; TTV: Total tumor volume; AFP: Alpha-fetoprotein; PEI: Percutaneous ethanol injection.

\section{Variations of Pre-Transplant Locoregional Therapies}

Although there are many types of pre-transplant locoregional therapies such as hepatic resection, ablation, and TACE, it is not clear which is best, and the application of each therapy, considering its cost-effectiveness, is essential. RFA is less expensive than TACE $[74,75]$ and is more effective in terms of tumor necrosis. However, its use is limited by the size, number, and location of tumors. Although TACE is the most commonly used pre-transplant treatment, it has the disadvantages of adverse effects due to toxicity and higher cost caused by anti-cancer drugs compared to transarterial embolization (TAE). A recent meta-analysis comparing the therapeutic effects of TACE and TAE demonstrated the non-superiority of TACE [76]. TACE is reported to have a tumor response in approximately $60 \%$ of cases $[37,45,77-81]$, and the frequency of complete tumor necrosis in excised specimens after LT was $16.7 \%$ to $44 \%$ [82-84]. Tumor response to RFA is reported to be slightly higher than with TACE [85-87]. The drop-out rate from the waiting list varies from 3-35\% with TACE, and it is around $25 \%$ with RFA $[45,78,85,86,88,89]$. 
Regarding complications related to locoregional therapies, a recent systematic review showed that TACE increased the risk of hepatic artery-related complications after LT $[79,90,91]$. However, more recently, Wallace et al. [92] reported that there was no difference in the incidence of hepatic artery thrombosis and other potentially TACE-related complications such as biliary stricture and leaks after LT between patients with and without TACE. On the other hand, there is concern that widespread adhesions after RFA may increase complications after LT. However, Haas et al. [93] reported that there was no difference in postoperative mortality and morbidity between patients with and without RFA after propensity score matching.

There are some reports comparing the results of LT after two different locoregional therapies. Gyori et al. [94] compared the results after TACE and RFA as BT, and they reported that both had similar transplant rates, tumor responses, and post-transplant outcomes. Ward et al. [12], comparing hepatectomy and RFA for single tumors, reported that RFA was more common for local recurrence, but hepatectomy was more common for distant metastases. In their study, explanted histopathology of patients treated with RFA showed pathological CR in $85.7 \%$ of patients. Therefore, they concluded that LT candidates with solitary $\mathrm{HCC}<3 \mathrm{~cm}$ should be treated with ablation. In recent years, drug-eluting bead TACE (DEB-TACE), degradable starch microsphere TACE (DSM-TACE), Yttrium-90 radioembolization, and stereotactic body radiation therapy (SBRT), etc., have been used as bridging and downstaging modalities instead of conventional methods. [95-102]. DEBTACE enables the maintenance of high concentrations of the drug in the tumor and fewer systemic adverse effects compared to conventional TACE by slowly and continuously releasing the anti-cancer drug locally. [103-105]. Frenette et al. [106] reported that both conventional TACE and DEB-TACE had similar frequencies of complete necrosis, posttransplant recurrence rates, and drop-outs from the waiting list. On the other hand, Nicolini et al. [107], comparing conventional TACE and DEB-TACE as pre-transplant locoregional therapy, reported that the recurrence-free survival rate was significantly better with DEBTACE than with conventional TACE $(61.5 \%$ vs. $87.4 \%, p=0.0493)$. Although DEB-TACE had few systemic side effects compared to conventional TACE, Fidelman et al. [108] reported that there were many complications for patients with borderline hepatic reserve, and it was not safe to use as a pre-transplant locoregional therapy for Child-Pugh B patients. DSM-TACE using DSM, which is decomposed by blood amylase and has a short arterial embolization period in the body of up to $50 \mathrm{~min}$, has been reported in cases of portal vein thrombosis [109-111]. Minici et al. [112,113] reported that DSM-TACE could be used safely and effectively as bridging or downstaging for patients with poor hepatic reserve (ChildPugh score 8-9 points). Radioembolization using Yttrium-90 is reported to treat target lesions more completely for early intermediate stage HCC than conventional TACE [114]. Radiolabeled particles are trapped at the precapillary level within the tumor vasculature, thus limiting exposure to the surrounding normal parenchyma. This allows higher dose delivery than with external beam radiation therapy [115]. Gabr et al. [116], examining 207 cases of Yttrium-90 therapy as bridging or downstaging prior to LT, reported tumor response with complete necrosis (100\%) in $94 \%$ of patients, extensive necrosis (51-99\%) in $29 \%$, and partial necrosis $(<50 \%)$ in $26 \%$, with a recurrence rate of $12 \%$ after LT. SBRT is an external beam radiation therapy method that precisely delivers a high dose of radiation to an extracranial target using either a single dose or a small number of high-dose fractions. The frequency of complete pathological necrosis of the tumor after SBRT varies from 13.3\% to $61.5 \%[101,117,118]$. Wong et al. [119] reported that pre-transplant SBRT had a higher frequency of complete pathological necrosis and a lower frequency of drop-outs from the waiting list compared to conventional bridging therapy.

In recent years, molecular-targeted therapies have been used alone or in combination with locoregional therapies as pre-transplant treatments $[120,121]$. Sorafenib is an oral multi-kinase inhibitor that has been effective in prolonging time-to-progression in patients with advanced cancer in two large phase III trials [122,123]. Recent evidence suggests that neo-angiogenic reactions are induced after TACE, which potentially enhances the tumor 
growth of untreated nodules or accelerates the development of de novo tumors [124]. Since sorafenib suppresses the growth of HCC by directly suppressing angiogenesis, it may be effective for bridging or downstaging when combined with TACE. However, at present, there are few reports that sorafenib was useful for bridging or downstaging before LT [121]. In addition to sorafenib, lenvatinib and regorafenib, which are also oral multi-kinase inhibitors, are used as therapeutic agents for advanced HCC. A meta-analysis showed that lenvatinib showed superior progression-free survival to sorafenib in patients with advanced HCC [125]. Regorafenib has also been shown to be useful as a second-line treatment after sorafenib [126]. Although it has been reported that successful down-staging was obtained with lenvatinib in a case report [127], no studies of lenvatinib and regorafenib as a neoadjuvant treatment before LT have been reported.

As explained above, there are various pre-transplant treatments for HCC used for bridging or downstaging. A complete understanding of the characteristics of each treatment is essential for selecting the optimal treatment, taking into account tumor burden, tumor site, and liver reserve.

\section{Comprehensive Assessment of Transplantable Tumor for Assigning Priority for Organ Allocation}

As mentioned earlier, T2 patients are given priority in the allocation system by UNOS in the USA. Even with the same T2 tumor, however, the risk of waiting list drop-out differs between cases with $\mathrm{T} 2$ at first presentation and cases after bridging or downstaging. Taking these facts into consideration, Mazzaferro [128] proposed the concept of a comprehensive assessment of transplantable tumor (TT), which involves classification into 8 subgroups considering the risk of drop-out based on tumor stage, suitability for locoregional therapies, and therapeutic effect, and gives priority to the group with the highest risk of dropout. The 8 subclasses are as follows: $\mathrm{TT}_{\mathrm{C}}$, no residual tumor after curative treatment of $\mathrm{HCC}$; $\mathrm{TTO}_{\mathrm{L}}$, no residual tumor after locoregional embolic therapies for HCC; TT1, single $\mathrm{HCC} \leq 2 \mathrm{~cm} ; \mathrm{TT0}$ NT, no residual tumor after treatment of a non-transplantable HCC (successful downstaging); $\mathrm{TT}_{\mathrm{FR}}$, transplantable $\mathrm{HCC}>\mathrm{T} 1$ at first presentation or recurrent

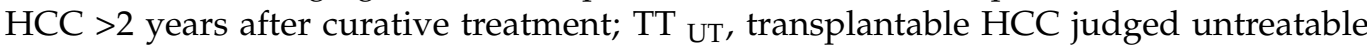
for reasons not captured by MELD (i.e., ascites); TT PR, partial response after complete bridge therapy in a transplantable tumor; TT ${ }_{\mathrm{DR}}$, transplant eligibility after downstaging (sustained partial response) or recurrent HCC $<2$ years after curative treatment of any HCC. From TT0 $\mathrm{C}$ to $\mathrm{TT}_{\mathrm{DR}}$, the stage of the tumor progresses, and the higher priority for organ allocation is given in this order. This concept was included in the Italian Consensus-Based Approach to Organ Allocation in Liver Transplantation [129]. Sandro et al. [130] validated the allocation system using the TT staging system by classifying the 8 subgroups of TT into 3 groups, the high-risk group ( $\mathrm{TT}_{\mathrm{DR}}, \mathrm{TT}_{\mathrm{PR}}$ ), the intermediate-risk group (TT0 ${ }_{\mathrm{NT}}$, $\left.\mathrm{TT}_{\mathrm{FR}}, \mathrm{TT}_{\mathrm{UT}}\right)$, and the low-risk group (TT1, TT0 $\left.\mathrm{L}, \mathrm{TT} 0_{\mathrm{C}}\right)$, in descending order of priority. They reported that the recurrence rate in the high-risk group was significantly lower when LT was performed within 2 months after staging $(10 \%$ vs. $33 \%$ for $<2$ and $>2$ months, $p=0.006$ ), which supported the validity of prioritization to the high-risk group by the TT staging system. However, the opposite result was obtained in the intermediate-risk group, and they concluded that further studies, including the definition of TT subgroups classified into the intermediate-risk group, are required.

\section{Conclusions}

The role of pre-transplant treatment, the characteristics of each treatment, and the results of LT after treatment were reviewed based on recent articles. The Milan criteria, which were proposed more than 20 years ago, are a very good morphological standard of LT for patients with HCC, and to date, pre-transplant treatment was aimed to keep the patients within these criteria for both patients within and outside the criteria. As a result, which patients need bridging, and the upper limit of tumor burden for downstaging have gradually become clear. It is expected that further studies with more effective bridging and 
downstaging therapies to obtain better survival and a lower recurrence rate of LT for HCC will be conducted.

Author Contributions: Conceptualization, K.O. and Y.T.; Writing-original draft preparation, K.O.; writing-review and editing, K.O. and Y.T. All authors have read and agreed to the published version of the manuscript.

Funding: This research received no external funding.

Conflicts of Interest: The authors declare no conflict of interest.

\section{References}

1. Bray, F.; Ferlay, J.; Soerjomataram, I.; Siegel, R.L.; Torre, L.A.; Jemal, A. Global cancer statistics 2018: GLOBOCAN estimates of incidence and mortality worldwide for 36 cancers in 185 countries. CA Cancer J. Clin. 2018, 68, 394-424. [CrossRef] [PubMed]

2. O'grady, J.G.; Polson, R.J.; Rolles, K.; Calne, R.Y.; Williams, R. Liver Transplantation for Malignant Disease. Ann. Surg. 1988, 207, 373-379. [CrossRef] [PubMed]

3. Ringe, B.; Pichlmayr, R.; Wittekind, C.; Tusch, G. Surgical treatment of hepatocellular carcinoma: Experience with liver resection and transplantation in 198 patients. World J. Surg. 1991, 15, 270-285. [CrossRef] [PubMed]

4. Iwatsuki, S.; Starzl, T.E.; Sheahan, D.G.; Yokoyama, I.; Demetris, A.J.; Todo, S.; Tzakis, A.G.; Van Thiel, D.H.; Carr, B.; Selby, R.; et al. Hepatic Resection Versus Transplantation for Hepatocellular Carcinoma. Ann. Surg. 1991, 214, 221-229. [CrossRef]

5. Bismuth, H.; Chiche, L.; Adam, R.; Castaing, D.; Diamond, T.; Dennison, A. Liver Resection Versus Transplantation for Hepatocellular Carcinoma in Cirrhotic Patients. Ann. Surg. 1993, 218, 145-151. [CrossRef]

6. Mazzaferro, V.M.; Regalia, E.; Doci, R.; Andreola, S.; Pulvirenti, A.; Bozzetti, F.; Montalto, F.; Ammatuna, M.; Morabito, A.; Gennari, L. Liver Transplantation for the Treatment of Small Hepatocellular Carcinomas in Patients with Cirrhosis. N. Engl. J. Med. 1996, 334, 693-700. [CrossRef]

7. Bruix, J.; Reig, M.; Sherman, M. Evidence-Based Diagnosis, Staging, and Treatment of Patients With Hepatocellular Carcinoma. Gastroenterology 2016, 150, 835-853. [CrossRef]

8. Parikh, N.D.; Singal, A.G. Model for end-stage liver disease exception points for treatment-responsive hepatocellular carcinoma. Clin. Liver Dis. 2016, 7, 97-100. [CrossRef]

9. Nagai, S.; Kitajima, T.; Yeddula, S.; Salgia, R.; Schilke, R.; Abouljoud, M.S.; Moonka, D. Effect of Mandatory 6-Month Waiting Period on Waitlist and Transplant Outcomes in Patients With Hepatocellular Carcinoma. Hepatology 2020, 72, $2051-2062$. [CrossRef]

10. Shimamura, T.; Akamatsu, N.; Fujiyoshi, M.; Kawaguchi, A.; Morita, S.; Kawasaki, S.; Uemoto, S.; Kokudo, N.; Hasegawa, K.; Ohdan, H.; et al. Expanded living-donor liver transplantation criteria for patients with hepatocellular carcinoma based on the Japanese nationwide survey: The 5-5-500 rule-A retrospective study. Transpl. Int. 2018, 32, 356-368. [CrossRef]

11. Yao, F.Y.; Bass, N.M.; Nikolai, B.; Davern, T.J.; Kerlan, R.; Wu, V.; Ascher, N.L.; Roberts, J.P. Liver transplantation for hepatocellular carcinoma: Analysis of survival according to the intention-to-treat principle and drop-out from the waiting list. Liver Transplant. 2002, 8, 873-883. [CrossRef]

12. Ward, E.M.; Sherif, A.E.; O’Neill, S.; Hughes, M.; Ireland, H.; Wigmore, S.J.; Adair, A. Clinical Outcomes of Ablation Compared with Resection for Single Hepatocellular Carcinoma Lesions, as a Primary Treatment or Bridging to Liver Transplantation: A Retrospective Comparative Study. Ann. Transplant. 2021, 26, e931980-1-e931980-12. [CrossRef]

13. Zheng, S.-S.; Xu, X.; Wu, J.; Chen, J.; Wang, W.-L.; Zhang, M.; Liang, T.-B.; Wu, L.-M. Liver Transplantation for Hepatocellular Carcinoma: Hangzhou Experiences. Transplantation 2008, 85, 1726-1732. [CrossRef]

14. Hernandez-Alejandro, R.; Toso, C.; Kneteman, N.M.; Majno, P.; Marotta, P.; Dufour, J.-F.; Meeberg, G. Total Tumor Volume and Alpha Fetoprotein for selection of transplant candidates with hepatocellular carcinoma: A prospective validation. Hepatology 2015, 62, 158-165.

15. Takada, Y.; Ito, T.; Ueda, M.; Sakamoto, S.; Haga, H.; Maetani, Y.; Ogawa, K.; Ogura, Y.; Oike, F.; Egawa, H.; et al. Living Donor Liver Transplantation for Patients with HCC Exceeding the Milan Criteria: A Proposal of Expanded Criteria. Dig. Dis. 2007, 25, 299-302. [CrossRef]

16. Taketomi, A.; Sanefuji, K.; Soejima, Y.; Yoshizumi, T.; Uhciyama, H.; Ikegami, T.; Harada, N.; Yamashita, Y.; Sugimachi, K.; Kayashima, H.; et al. Impact of Des-Gamma-Carboxy Prothrombin and Tumor Size on the Recurrence of Hepatocellular Carcinoma After Living Donor Liver Transplantation. Transplantation 2009, 87, 531-537. [CrossRef]

17. Hsu, C.C.; Chen, C.L.; Wang, C.C.; Lin, C.C.; Yong, C.C.; Wang, S.H.; Liu, Y.W.; Lin, T.L.; Lee, W.F.; Lin, Y.H.; et al. Combination of FDG-PET and UCSF Criteria for Predicting HCC Recurrence After Living Donor Liver Transplantation. Transplantation 2016, 100, 1925-1932. [CrossRef]

18. Schoenberg, M.B.; Anger, H.J.W.; Bucher, J.N.; Denk, G.; De Toni, E.N.; Seidensticker, M.; Andrassy, J.; Angele, M.K.; Werner, J.; Guba, M.O. Liver Transplantation for Extended Criteria Hepatocellular Carcinoma Using Stable Response to Locoregional Therapy and Alpha-Fetoprotein as Selection Criteria. Visc. Med. 2020, 36, 506-515. [CrossRef] 
19. Duvoux, C.; Roudot-Thoraval, F.; Decaens, T.; Pessione, F.; Badran, H.; Piardi, T.; Francoz, C.; Compagnon, P.; Vanlemmens, C.; Dumortier, J.; et al. Liver Transplantation for Hepatocellular Carcinoma: A Model Including $\alpha$-Fetoprotein Improves the Performance of Milan Criteria. Gastroenterology 2012, 143, 986-994. [CrossRef]

20. Halazun, K.J.; Najjar, M.; Abdelmessih, R.M.; Samstein, B.; Griesemer, A.D.; Guarrera, J.V.; Kato, T.; Verna, E.C.; Emond, J.C.; Brown, R.S., Jr. Recurrence After Liver Transplantation for Hepatocellular Carcinoma: A New MORAL to the Story. Ann. Surg. 2017, 265, 557-564. [CrossRef]

21. Sasaki, K.; Firl, D.J.; Hashimoto, K.; Fujiki, M.; Diago-Uso, T.; Quintini, C.; Eghtesad, B.; Fung, J.J.; Aucejo, F.N.; Miller, C.M. Development and validation of the HALT-HCC score to predict mortality in liver transplant recipients with hepatocellular carcinoma: A retrospective cohort analysis. Lancet Gastroenterol. Hepatol. 2017, 2, 595-603. [CrossRef]

22. Ivanics, T.; Nelson, W.; Patel, M.S.; Claasen, M.P.; Lau, L.; Gorgen, A.; Abreu, P.; Goldenberg, A.; Erdman, L.; Sapisochin, G. The Toronto Postliver Transplantation Hepatocellular Carcinoma Recurrence Calculator: A Machine Learning Approach. Liver Transplant. 2021. [CrossRef] [PubMed]

23. American College of Radiology (ACR). Archived Releases; LI-RADS Version 1.0. ACR Website. Available online: https: / / www.acr.org/Clinical-Resources/Reporting-and-Data-Systems/LI-RADS/LI-RADS1 (accesed on 4 January 2022).

24. Chernyak, V.; Fowler, K.J.; Kamaya, A.; Kielar, A.Z.; Elsayes, K.M.; Bashir, M.R.; Kono, Y.; Do, R.K.; Mitchell, D.G.; Singal, A.G.; et al. Liver Imaging Reporting and Data System (LI-RADS) Version 2018: Imaging of Hepatocellular Carcinoma in At-Risk Patients. Radiology 2018, 289, 816-830. [CrossRef] [PubMed]

25. Tang, E.S.-T.; Hall, G.; Yu, D.; Menard, A.; Hopman, W.; Nanji, S. Predictors and Cumulative Frequency of Hepatocellular Carcinoma in High and Intermediate LI-RADS Lesions: A Cohort Study from a Canadian Academic Institution. Ann. Surg. Oncol. 2019, 26, 2560-2567. [CrossRef]

26. Mazzaferro, V.; Sposito, C.; Zhou, J.; Pinna, A.D.; De Carlis, L.; Fan, J.; Cescon, M.; Di Sandro, S.; Yi-Feng, H.; Lauterio, A.; et al. Metroticket 2.0 Model for Analysis of Competing Risks of Death After Liver Transplantation for Hepatocellular Carcinoma. Gastroenterology 2018, 154, 128-139. [CrossRef]

27. Centonze, L.; Di Sandro, S.; Lauterio, A.; De Carlis, R.; Sgrazzutti, C.; Ciulli, C.; Vella, I.; Vicentin, I.; Incarbone, N.; Bagnardi, V.; et al. A retrospective single-centre analysis of the oncological impact of LI-RADS classification applied to Metroticket 2.0 calculator in liver transplantation: Every nodule matters. Transpl. Int. 2021, 34, 1712-1721. [CrossRef]

28. Llovet, J.M.; Fuster, J.; Bruix, J. Intention-to-treat analysis of surgical treatment for early hepatocellular carcinoma: Resection versus transplantation. Hepatology 1999, 30, 1434-1440. [CrossRef]

29. Ashoori, N.; Bamberg, F.; Paprottka, P.; Rentsch, M.; Kolligs, F.; Siegert, S.; Peporte, A.; Al-Tubaikh, J.; D’Anastasi, M.; Hoffmann, R.; et al. Multimodality Treatment for Early-Stage Hepatocellular Carcinoma: A Bridging Therapy for Liver Transplantation. Digestion 2012, 86, 338-348. [CrossRef]

30. Habibollahi, P.; Hunt, S.; Bitterman, T.; Gade, T.P.; Soulen, M.C.; Nadolski, G. Definitive locoregional therapy (LRT) versus bridging LRT and liver transplantation with wait-and-not-treat approach for very early stage hepatocellular carcinoma. Diagn. Interv. Radiol. 2018, 24, 213-218. [CrossRef]

31. Mehta, N.; Sarkar, M.; Dodge, J.L.; Fidelman, N.; Roberts, J.P.; Yao, F.Y. Intention to treat outcome of T1 hepatocellular carcinoma with the "wait and not ablate" approach until meeting T2 criteria for liver transplant listing. Liver Transplant. 2015, 22, 178-187. [CrossRef]

32. Lai, Q.; Vitale, A.; Iesari, S.; Finkenstedt, A.; Mennini, G.; Onali, S.; Hoppe-Lotichius, M.; Manzia, T.M.; Nicolini, D.; Avolio, A.W.; et al. The Intention-to-Treat Effect of Bridging Treatments in the Setting of Milan Criteria-In Patients Waiting for Liver Transplantation. Liver Transplant. 2019, 25, 1023-1033. [CrossRef]

33. Tan, C.H.N.; Yu, Y.; Tan, Y.R.N.; Lim, B.L.K.; Iyer, S.G.; Madhavan, K.; Kow, A.W.C. Bridging therapies to liver transplantation for hepatocellular carcinoma: A bridge to nowhere? Ann. Hepatobiliary Pancreat. Surg. 2018, 22, 27-35. [CrossRef]

34. European Association For The Study Of The Liver; European Organisation for Research and Treatment of Cancer. EASL-EORTC clinical practice guidelines: Management of hepatocellular carcinoma. J. Hepatol. 2012, 56, 908-943. [CrossRef]

35. Clavien, P.-A.; Lesurtel, M.; Bossuyt, P.M.; Gores, G.J.; Langer, B.; Perrier, A. Recommendations for liver transplantation for hepatocellular carcinoma: An international consensus conference report. Lancet Oncol. 2012, 13, e11-e22. [CrossRef]

36. Kim, J.; Kwon, C.; Joh, J.-W.; Choi, M.; Lee, J.; Koh, K.; Paik, S.; Kim, G.; Kim, S.; Lee, S.-K.; et al. Effectiveness of Locoregional Therapy Before Living Donor Liver Transplantation in Patients With Hepatocellular Carcinoma Who Meet the Milan Criteria. Transplant. Proc. 2012, 44, 403-408. [CrossRef]

37. Decaens, T.; Roudot-Thoraval, F.; Bresson-Hadni, S.; Meyer, C.; Gugenheim, J.; Durand, F.; Bernard, P.; Boillot, O.; Boudjema, K.; Calmus, Y.; et al. Impact of pretransplantation transarterial chemoembolization on survival and recurrence after liver transplantation for hepatocellular carcinoma. Liver Transplant. 2005, 11, 767-775. [CrossRef]

38. Agopian, V.G.; Harlander-Locke, M.P.; Ruiz, R.M.; Klintmalm, G.B.; Senguttuvan, S.; Florman, S.S.; Haydel, B.; Hoteit, M.; Levine, M.H.; Lee, D.D.; et al. Impact of Pretransplant Bridging Locoregional Therapy for Patients With Hepatocellular Carcinoma Within Milan Criteria Undergoing Liver Transplantation: Analysis of 3601 Patients From the US Multicenter HCC Transplant Consortium. Ann. Surg. 2017, 266, 525-535. [CrossRef]

39. Lee, S.; Kim, K.W.; Song, G.-W.; Kwon, J.H.; Hwang, S.; Kim, K.-H.; Ahn, C.-S.; Moon, D.-B.; Park, G.-C.; Lee, S.-G. The Real Impact of Bridging or Downstaging on Survival Outcomes after Liver Transplantation for Hepatocellular Carcinoma. Liver Cancer 2020, 9, 721-733. [CrossRef] 
40. Oligane, H.C.; Xing, M.; Kim, H.S. Effect of Bridging Local-Regional Therapy on Recurrence of Hepatocellular Carcinoma and Survival after Orthotopic Liver Transplantation. Radiology 2017, 282, 869-879. [CrossRef]

41. Renner, P.; Da Silva, T.; Schnitzbauer, A.A.; Verloh, N.; Schlitt, H.J.; Geissler, E.K. Hepatocellular carcinoma progression during bridging before liver transplantation. BJS Open 2021, 5, zrab005. [CrossRef]

42. Ogawa, K.; Kaido, T.; Okajima, H.; Fujimoto, Y.; Yoshizawa, A.; Yagi, S.; Hori, T.; Iida, T.; Takada, Y.; Uemoto, S. Impact of pretreatments on outcomes after living donor liver transplantation for hepatocellular carcinoma. J. Hepato-Biliary-Pancreatic Sci. 2018, 26, 73-81. [CrossRef]

43. Lai, Q.; Iesari, S.; Sandri, G.B.L.; Lerut, J. Des-Gamma-Carboxy Prothrombin in Hepatocellular Cancer Patients Waiting for Liver Transplant: A Systematic Review and Meta-Analysis. Int. J. Biol. Markers 2017, 32, 370-374. [CrossRef]

44. Agopian, V.G.; Morshedi, M.M.; McWilliams, J.; Harlander-Locke, M.P.; Markovic, D.; Zarrinpar, A.; Kaldas, F.M.; Farmer, D.G.; Yersiz, H.; Hiatt, J.R.; et al. Complete pathologic response to pretransplant locoregional therapy for hepatocellular carcinoma defines cancer cure after liver transplantation: Analysis of 501 consecutively treated patients. Ann. Surg. 2015, 262, 536-545. [CrossRef]

45. Millonig, G.; Graziadei, I.W.; Freund, M.C.; Jaschke, W.; Stadlmann, S.; Ladurner, R.; Margreiter, R.; Vogel, W. Response to preoperative chemoembolization correlates with outcome after liver transplantation in patients with hepatocellular carcinoma. Liver Transplant. 2007, 13, 272-279. [CrossRef]

46. Xu, M.; Doyle, M.M.; Banan, B.; Vachharajani, N.; Wang, X.; Saad, N.; Fowler, K.; Brunt, E.M.; Lin, Y.; Chapman, W.C. Neoadjuvant Locoregional Therapy and Recurrent Hepatocellular Carcinoma after Liver Transplantation. J. Am. Coll. Surg. 2017, 225, 28-40, Erratum in: J. Am. Coll. Surg. 2018, 226, 115. [CrossRef]

47. Pompili, M.; Pacella, C.M.; Francica, G.; Angelico, M.; Tisone, G.; Craboledda, P.; Nicolardi, E.; Rapaccini, G.L.; Gasbarrini, G. Percutaneous laser ablation of hepatocellular carcinoma in patients with liver cirrhosis awaiting liver transplantation. Eur. J. Radiol. 2010, 74, e6-e11. [CrossRef]

48. Yao, F.Y.; Kerlan, R.K., Jr.; Hirose, R.; Davern, T.J., 3rd.; Bass, N.M.; Feng, S.; Peters, M.; Terrault, N.; Freise, C.E.; Ascher, N.L.; et al. Excellent outcome following down-staging of hepatocellular carcinoma prior to liver transplantation: An intention-to-treat analysis. Hepatology 2008, 48, 819-827. [CrossRef]

49. Marin, H.L.; Furth, E.E.; Olthoff, K.; Shaked, A.; Soulen, M.C. Histopathologic outcome of neoadjuvant image-guided therapy of hepatocellular carcinoma. J. Gastrointest. Liver Dis. 2009, 18, 169-179.

50. Shaker, M.K.; Montasser, I.F.; Sakr, M.; Elgharib, M.; Dabbous, H.M.; Ebada, H.; El Dorry, A.; Bahaa, M.; El Meteini, M. Efficacy of locoregional treatment for hepatocellular carcinoma prior to living donor liver transplantation: A report from a single center in Egypt. J. Hepatocell. Carcinoma 2018, 5, 29-36. [CrossRef] [PubMed]

51. Rubinstein, M.M.; Kaubisch, A.; Kinkhabwala, M.; Reinus, J.; Liu, Q.; Chuy, J.W. Bridging therapy effectiveness in the treatment of hepatocellular carcinoma prior to orthotopic liver transplantation. J. Gastrointest. Oncol. 2017, 8, 1051-1055. [CrossRef] [PubMed]

52. Lee, M.W.; Raman, S.S.; Asvadi, N.H.; Siripongsakun, S.; Hicks, R.M.; Chen, J.; Worakitsitisatorn, A.; McWilliams, J.; Tong, M.J.; Finn, R.S.; et al. Radiofrequency ablation of hepatocellular carcinoma as bridge therapy to liver transplantation: A 10-year intention-to-treat analysis. Hepatology 2017, 65, 1979-1990. [CrossRef]

53. Na, G.H.; Kim, E.Y.; Hong, T.H.; You, Y.K.; Kim, D.G. Effects of loco regional treatments before living donor liver transplantation on overall survival and recurrence-free survival in South Korean patients with hepatocellular carcinoma. HPB 2015, 18, 98-106. [CrossRef]

54. Affonso, B.B.; Galastri, F.L.; da Motta Leal Filho, J.M.; Nasser, F.; Falsarella, P.M.; Cavalcante, R.N.; De Almeida, M.D.; Felga, G.E.G.; Valle, L.G.M.; Wolosker, N. Long-term outcomes of hepatocellular carcinoma that underwent chemoembolization for bridging or downstaging. World J. Gastroenterol. 2019, 25, 5687-5701. [CrossRef]

55. Xing, M.; Sakaria, S.; Dhanasekaran, R.; Parekh, S.; Spivey, J.; Knechtle, S.J.; Zhang, D.; Kim, H.S. Bridging Locoregional Therapy Prolongs Survival in Patients Listed for Liver Transplant with Hepatocellular Carcinoma. Cardiovasc. Interv. Radiol. 2016, 40, 410-420. [CrossRef]

56. Vitale, A.; Scolari, F.; Bertacco, A.; Gringeri, E.; D’Amico, F.; Bassi, D.; D'Amico, F.E.; Angeli, P.; Burra, P.; Lai, Q.; et al. Sustained Complete Response after Biological Downstaging in Patients with Hepatocellular Carcinoma: XXL-Like Prioritization for Liver Transplantation or "Wait and See" Strategy? Cancers 2021, 13, 2406. [CrossRef]

57. Murali, A.R.; Romero-Marrero, C.; Miller, C.; Aucejo, F.; Levitin, A.; Gill, A.; McLennan, G.; Karuppasamy, K.; Zein, N.N.; Lopez, R.; et al. Predictors of Successful Downstaging of Hepatocellular Carcinoma Outside Milan Criteria. Transplantation 2016, 100, 2391-2397. [CrossRef]

58. Mehta, N.; Guy, J.; Frenette, C.T.; Dodge, J.L.; Osorio, R.W.; Minteer, W.B.; Roberts, J.P.; Yao, F.Y. Excellent Outcomes of Liver Transplantation Following Down-Staging of Hepatocellular Carcinoma to Within Milan Criteria: A Multicenter Study. Clin. Gastroenterol. Hepatol. 2018, 16, 955-964. [CrossRef]

59. Bova, V.; Miraglia, R.; Maruzzelli, L.; Vizzini, G.B.; Luca, A. Predictive Factors of Downstaging of Hepatocellular Carcinoma Beyond the Milan Criteria Treated with Intra-arterial Therapies. Cardiovasc. Interv. Radiol. 2012, 36, 433-439. [CrossRef]

60. Yao, F.Y.; Mehta, N.; Flemming, J.; Dodge, J.; Hameed, B.; Fix, O.; Hirose, R.; Fidelman, N.; Kerlan, R.K., Jr.; Roberts, J.P. Downstaging of hepatocellular cancer before liver transplant: Long-term outcome compared to tumors within Milan criteria. Hepatology 2015, 61, 1968-1977. [CrossRef] 
61. Kim, Y.; Stahl, C.C.; Makramalla, A.; Olowokure, O.O.; Ristagno, R.L.; Dhar, V.K.; Schoech, M.R.; Chadalavada, S.; Latif, T.; Kharofa, J.; et al. Downstaging therapy followed by liver transplantation for hepatocellular carcinoma beyond Milan criteria. Surgery 2017, 162, 1250-1258. [CrossRef] [PubMed]

62. Massarollo, P.; Coppini, A.; Salzedas-Netto, A.; Coelho, F.; Minami, T.; Gonzalez, A. Favorable Long-term Outcome in Patients Submitted to Liver Transplantation After Downstaging of Hepatocellular Carcinoma According to a Brazilian Selection Protocol. Transplant. Proc. 2016, 48, 2338-2340. [CrossRef] [PubMed]

63. Chapman, W.C.; Garcia-Aroz, S.; Vachharajani, N.; Fowler, K.; Saad, N.; Lin, Y.; Wellen, J.; Tan, B.; Khan, A.S.; Doyle, M.M. Liver Transplantation for Advanced Hepatocellular Carcinoma after Downstaging Without Up-Front Stage Restrictions. J. Am. Coll. Surg. 2017, 224, 610-621. [CrossRef] [PubMed]

64. Ravaioli, M.; Odaldi, F.; Cucchetti, A.; Trevisani, F.; Piscaglia, F.; De Pace, V.; Bertuzzo, V.R.; Neri, F.; Golfieri, R.; Cappelli, A.; et al. Long term results of down-staging and liver transplantation for patients with hepatocellular carcinoma beyond the conventional criteria. Sci. Rep. 2019, 9, 3781. [CrossRef]

65. Kim, D.G.; Lee, J.G.; Joo, D.J.; Kim, S.; Kim, M.S. Favourable outcome of pathologic downstaging by locoregional treatment for hepatocellular carcinoma in liver transplantation. Sci. Rep. 2019, 9, 10386. [CrossRef]

66. Kamo, N.; Kaido, T.; Yagi, S.; Okajima, H.; Uemoto, S. Liver Transplantation for Intermediate-Stage Hepatocellular Carcinoma Liver Cancer 2018, 7, 179-189. [CrossRef]

67. Kaido, T.; Ogawa, K.; Mori, A.; Fujimoto, Y.; Ito, T.; Tomiyama, K.; Takada, Y.; Uemoto, S. Usefulness of the Kyoto criteria as expanded selection criteria for liver transplantation for hepatocellular carcinoma. Surgery 2013, 154, 1053-1060. [CrossRef]

68. Mazzaferro, V.; Citterio, D.; Bhoori, S.; Bongini, M.; Miceli, R.; De Carlis, L.; Colledan, M.; Salizzoni, M.; Romagnoli, R.; Antonelli, B.; et al. Liver transplantation in hepatocellular carcinoma after tumour downstaging (XXL): A randomised, controlled, phase 2b/3 trial. Lancet Oncol. 2020, 21, 947-956. [CrossRef]

69. Sinha, J.; Mehta, N.; Dodge, J.L.; Poltavskiy, E.; Roberts, J.; Yao, F. Are There Upper Limits in Tumor Burden for Down-Staging of Hepatocellular Carcinoma to Liver Transplant? Analysis of the All-Comers Protocol. Hepatology 2019, 70, 1185-1196. [CrossRef]

70. Mehta, N.; Dodge, J.L.; Grab, J.D.; Yao, F.Y. National Experience on Down-Staging of Hepatocellular Carcinoma Before Liver Transplant: Influence of Tumor Burden, Alpha-Fetoprotein, and Wait Time. Hepatology 2020, 71, 943-954. [CrossRef]

71. Wu, T.-H.; Wang, Y.-C.; Cheng, C.-H.; Lee, C.-F.; Wu, T.-J.; Chou, H.-S.; Chan, K.-M.; Lee, W.-C. Outcomes associated with the intention of locoregional therapy prior to living donor liver transplantation for hepatocellular carcinoma. World J. Gastrointest. Surg. 2020, 12, 17-27. [CrossRef]

72. Toso, C.; Meeberg, G.; Andres, A.; Shore, C.; Saunders, C.; Bigam, D.L.; Shapiro, A.M.J.; Compagnon, P.; Berney, T.; Majno, P.; et al. Downstaging prior to liver transplantation for hepatocellular carcinoma: Advisable but at the price of an increased risk of cancer recurrence-A retrospective study. Transpl. Int. 2018, 32, 163-172. [CrossRef]

73. Soin, A.S.; Bhangui, P.; Kataria, T.; Baijal, S.S.; Piplani, T.; Gautam, D.; Choudhary, N.S.; Thiagarajan, S.; Rastogi, A.; Saraf, N.; et al. Experience With LDLT in Patients With Hepatocellular Carcinoma and Portal Vein Tumor Thrombosis Postdownstaging. Transplantation 2020, 104, 2334-2345. [CrossRef]

74. De Simone, P.; Vignali, C.; Petruccelli, S.; Carrai, P.; Coletti, L.; Montin, U.; Catalano, G.; Urbani, L.; Filipponi, F. Cost Analysis of Tumor Downsizing for Hepatocellular Carcinoma Liver Transplant Candidates. Transplant. Proc. 2006, 38, 3561-3563. [CrossRef]

75. Thein, H.; Isaranuwatchai, W.; Qiao, Y.; Wong, K.; Sapisochin, G.; Chan, K.K.W.; Yoshida, E.M.; Earle, C.C. Cost-effectiveness analysis of potentially curative and combination treatments for hepatocellular carcinoma with person-level data in a Canadian setting. Cancer Med. 2017, 6, 2017-2033. [CrossRef]

76. Facciorusso, A.; Bellanti, F.; Villani, R.; Salvatore, V.; Muscatiello, N.; Piscaglia, F.; Vendemiale, G.; Serviddio, G. Transarterial chemoembolization vs bland embolization in hepatocellular carcinoma: A meta-analysis of randomized trials. United Eur. Gastroenterol. J. 2017, 5, 511-518. [CrossRef]

77. Graziadei, I.W.; Sandmueller, H.; Waldenberger, P.; Koenigsrainer, A.; Nachbaur, K.; Jaschke, W.; Margreiter, R.; Vogel, W. Chemoembolization followed by liver transplantation for hepatocellular carcinoma impedes tumor progression while on the waiting list and leads to excellent outcome. Liver Transplant. 2003, 9, 557-563. [CrossRef]

78. Hayashi, P.H.; Ludkowski, M.; Forman, L.M.; Osgood, M.; Johnson, S.; Kugelmas, M.; Trotter, J.F.; Bak, T.; Wachs, M.; Kam, I.; et al. Hepatic Artery Chemoembolization for Hepatocellular Carcinoma in Patients Listed for Liver Transplantation. Arab. Archaeol. Epigr. 2004, 4, 782-787. [CrossRef]

79. Tsochatzis, E.; Garcovich, M.; Marelli, L.; Papastergiou, V.; Fatourou, E.; Rodríguez-Perálvarez, M.; Germani, G.; Davies, N.; Yu, D.; Luong, T.V.; et al. Transarterial embolization as neo-adjuvant therapy pretransplantation in patients with hepatocellular carcinoma. Liver Int. 2013, 33, 944-949. [CrossRef]

80. Golfieri, R.; Cappelli, A.; Cucchetti, A.; Piscaglia, F.; Carpenzano, M.; Peri, E.; Ravaioli, M.; D’Errico-Grigioni, A.; Pinna, A.D.; Bolondi, L. Efficacy of selective transarterial chemoembolization in inducing tumor necrosis in small $(<5 \mathrm{~cm})$ hepatocellular carcinomas. Hepatology 2011, 53, 1580-1589. [CrossRef]

81. Hołówko, W.; Wróblewski, T.; Wojtaszek, M.; Grąt, M.; Kobryń, K.; Ziarkiewicz-Wróblewska, B.; Krawczyk, M. Transarterial Chemoembolization Prior to Liver Transplantation in Patients with Hepatocellular Carcinoma. Ann. Transplant. 2015, 20, 764-768. [CrossRef] 
82. Herber, S.; Biesterfeld, S.; Franz, U.; Schneider, J.; Thies, J.; Schuchmann, M.; Düber, C.; Pitton, M.; Otto, G. Correlation of Multislice CT and Histomorphology in HCC Following TACE: Predictors of Outcome. Cardiovasc. Interv. Radiol. 2008, 31, 768-777. [CrossRef] [PubMed]

83. Yao, F.Y.; Hirose, R.; LaBerge, J.M.; Davern, T.J., 3rd.; Bass, N.M.; Kerlan, R.K., Jr.; Merriman, R.; Feng, S.; Freise, C.E.; Ascher, N.L.; et al. A prospective study on downstaging of hepatocellular carcinoma prior to liver transplantation. Liver Transpl. 2005, 11, 1505-1514. [CrossRef]

84. Zhang, W.; Xu, A.-H.; Wang, W.; Wu, Y.-H.; Sun, Q.-L.; Shu, C. Radiological appearance of hepatocellular carcinoma predicts the response to trans-arterial chemoembolization in patients undergoing liver transplantation. BMC Cancer 2019, 19, 1041. [CrossRef]

85. Mazzaferro, V.; Battiston, C.; Perrone, S.; Pulvirenti, A.; Regalia, E.; Romito, R.; Sarli, D.; Schiavo, M.; Garbagnati, F.; Marchiano, A.; et al. Radiofrequency ablation of small hepatocellular carcinoma in cirrhotic patients awaiting liver transplantation: A prospective study. Ann. Surg. 2004, 240, 900-909. [CrossRef]

86. Lu, D.S.K.; Yu, N.C.; Raman, S.S.; Lassman, C.; Tong, M.J.; Britten, C.; Durazo, F.; Saab, S.; Han, S.; Finn, R.; et al. Percutaneous radiofrequency ablation of hepatocellular carcinoma as a bridge to liver transplantation. Hepatology 2005, 41, 1130-1137. [CrossRef]

87. Pompili, M.; Mirante, V.G.; Rondinara, G.; Fassati, L.R.; Piscaglia, F.; Agnes, S.; Covino, M.; Ravaioli, M.; Fagiuoli, S.; Gasbarrini, G.; et al. Percutaneous ablation procedures in cirrhotic patients with hepatocellular carcinoma submitted to liver transplantation: Assessment of efficacy at explant analysis and of safety for tumor recurrence. Liver Transplant. 2005, 11, 1117-1126. [CrossRef]

88. Majno, P.; Giostra, E.; Mentha, G. Management of hepatocellular carcinoma on the waiting list before liver transplantation: Time for controlled trials? Liver Transpl. 2007, 13, S27-S35. [CrossRef]

89. Fontana, R.J.; Hamidullah, H.; Nghiem, H.V.; Greenson, J.K.; Hussain, H.K.; Marrero, J.A.; Rudich, S.; McClure, L.A.; Arenas, J.D. Percutaneous radiofrequency thermal ablation of hepatocellular carcinoma: A safe and effective bridge to liver transplantation. Liver Transplant. 2002, 8, 1165-1174. [CrossRef]

90. Si, T.; Chen, Y.; Ma, D.; Gong, X.; Guan, R.; Shen, B.; Peng, C. Transarterial chemoembolization prior to liver transplantation for patients with hepatocellular carcinoma: A meta-analysis. J. Gastroenterol. Hepatol. 2017, 32, 1286-1294. [CrossRef] [PubMed]

91. Sneiders, D.; Houwen, T.; Pengel, L.H.; Polak, W.G.; Dor, F.J.M.F.; Hartog, H. Systematic Review and Meta-Analysis of Posttransplant Hepatic Artery and Biliary Complications in Patients Treated With Transarterial Chemoembolization Before Liver Transplantation. Transplantation 2018, 102, 88-96. [CrossRef] [PubMed]

92. Wallace, D.; Cowling, T.E.; Walker, K.; Suddle, A.; Gimson, A.; Rowe, I.; Callaghan, C.; Sapisochin, G.; Mehta, N.; Heaton, N.; et al Liver transplantation outcomes after transarterial chemotherapy for hepatocellular carcinoma. J. Br. Surg. 2020, 107, 1183-1191. [CrossRef]

93. De Haas, R.J.; Lim, C.; Ricci, C.; Lahat, E.; Fuentes, L.; Salloum, C.; Azoulay, D. Local Ablation Does Not Worsen Perioperative Outcomes After Liver Transplant for Hepatocellular Carcinoma. Am. J. Roentgenol. 2019, 213, 702-709. [CrossRef]

94. Györi, G.P.; Felsenreich, D.M.; Silberhumer, G.R.; Soliman, T.; Berlakovich, G.A. Multimodality locoregional treatment strategies for bridging HCC patients before liver transplantation. Eur. Surg. 2017, 49, 236-243. [CrossRef]

95. Yu, C.-Y.; Ou, H.-Y.; Weng, C.-C.; Huang, T.-L.; Chen, T.-Y.; Leung-Chit, L.; Hsu, H.-W.; Chen, C.-L.; Cheng, Y.-F. Drug-Eluting Bead Transarterial Chemoembolization as Bridge Therapy for Hepatocellular Carcinoma Before Living-Donor Liver Transplantation. Transplant. Proc. 2016, 48, 1045-1048. [CrossRef]

96. Orlacchio, A.; Chegai, F.; Merolla, S.; Francioso, S.; Del Giudice, C.; Angelico, M.; Tisone, G.; Simonetti, G. Downstaging disease in patients with hepatocellular carcinoma outside up-to-seven criteria: Strategies using degradable starch microspheres transcatheter arterial chemo-embolization. World J. Hepatol. 2015, 7, 1694-1700. [CrossRef]

97. Galastri, F.L.; Nasser, F.; Affonso, B.B.; Valle, L.G.M.; Odísio, B.C.; Filho, J.M.M.-L.; Salvalaggio, P.R.; Garcia, R.G.; De Almeida, M.D.; Baroni, R.H.; et al. Imaging response predictors following drug eluting beads chemoembolization in the neoadjuvant liver transplant treatment of hepatocellular carcinoma. World J. Hepatol. 2020, 12, 21-33. [CrossRef]

98. Salem, R.; Lewandowski, R.J.; Kulik, L.; Wang, E.; Riaz, A.; Ryu, R.K.; Sato, K.T.; Gupta, R.; Nikolaidis, P.; Miller, F.H.; et al Radioembolization Results in Longer Time-to-Progression and Reduced Toxicity Compared With Chemoembolization in Patients With Hepatocellular Carcinoma. Gastroenterology 2011, 140, 497-507. [CrossRef]

99. Radunz, S.; Treckmann, J.; Baba, H.A.; Best, J.; Müller, S.; Theysohn, J.M.; Paul, A.; Benkö, T. Long-Term Outcome After Liver Transplantation for Hepatocellular Carcinoma Following Yttrium-90 Radioembolization Bridging Treatment. Ann. Transplant. 2017, 22, 215-221. [CrossRef]

100. Villalobos, A.; Wagstaff, W.; Guo, M.; Zhang, J.; Bercu, Z.; Whitmore, M.J.; Cristescu, M.M.; Majdalany, B.S.; Wedd, J.; Akce, M.; et al. Predictors of Successful Yttrium-90 Radioembolization Bridging or Downstaging in Patients with Hepatocellular Carcinoma. Can. J. Gastroenterol. Hepatol. 2021, 2021, 9926704. [CrossRef]

101. Sapisochin, G.; Barry, A.; Doherty, M.; Fischer, S.; Goldaracena, N.; Rosales, R.; Russo, M.; Beecroft, R.; Ghanekar, A.; Bhat, M.; et al. Stereotactic body radiotherapy vs. TACE or RFA as a bridge to transplant in patients with hepatocellular carcinoma. An intention-to-treat analysis. J. Hepatol. 2017, 67, 92-99. [CrossRef]

102. Moore, A.; Cohen-Naftaly, M.; Tobar, A.; Kundel, Y.; Benjaminov, O.; Braun, M.; Issachar, A.; Mor, E.; Sarfaty, M.; Bragilovski, D.; et al. Stereotactic body radiation therapy (SBRT) for definitive treatment and as a bridge to liver transplantation in early stage inoperable Hepatocellular carcinoma. Radiat. Oncol. 2017, 12, 163. [CrossRef] 
103. Varela, M.; Real, M.I.; Burrel, M.; Forner, A.; Sala, M.; Brunet, M.; Ayuso, C.; Castells, L.; Montañá, X.; Llovet, J.M.; et al. Chemoembolization of hepatocellular carcinoma with drug eluting beads: Efficacy and doxorubicin pharmacokinetics. J. Hepatol. 2007, 46, 474-481. [CrossRef] [PubMed]

104. Lammer, J.; Malagari, K.; Vogl, T.; Pilleul, F.; Denys, A.; Watkinson, A.; Pitton, M.; Sergent, G.; Pfammatter, T.; Terraz, S.; et al. Prospective Randomized Study of Doxorubicin-Eluting-Bead Embolization in the Treatment of Hepatocellular Carcinoma: Results of the PRECISION V Study. Cardiovasc. Interv. Radiol. 2009, 33, 41-52. [CrossRef] [PubMed]

105. Lewis, A.L.; Taylor, R.R.; Hall, B.; Gonzalez, M.V.; Willis, S.L.; Stratford, P.W. Pharmacokinetic and Safety Study of Doxorubicineluting Beads in a Porcine Model of Hepatic Arterial Embolization. J. Vasc. Interv. Radiol. 2006, 17, 1335-1343. [CrossRef] [PubMed]

106. Frenette, C.T.; Osorio, R.C.; Stark, J.; Fok, B.; Boktour, M.R.; Guy, J.; Rhee, J.; Osorio, R.W. Conventional TACE and drugeluting bead TACE as locoregional therapy before orthotopic liver transplantation: Comparison of explant pathologic response. Transplantation 2014, 98, 781-787. [CrossRef] [PubMed]

107. Nicolini, D.; Svegliati-Baroni, G.; Candelari, R.; Mincarelli, C.; Mandolesi, A.; Bearzi, I.; Mocchegiani, F.; Vecchi, A.; Montalti, R.; Benedetti, A.; et al. Doxorubicin-eluting bead vs conventional transcatheter arterial chemoembolization for hepatocellular carcinoma before liver transplantation. World J. Gastroenterol. 2013, 19, 5622-5632. [CrossRef]

108. Fidelman, N.; Johanson, C.; Kohi, M.P.; Kolli, K.P.; Kohlbrenner, R.M.; Lehrman, E.D.; Taylor, A.G.; Kelley, R.K.; Yao, F.Y.; Roberts, J.P.; et al. Prospective Phase II trial of drug-eluting bead chemoembolization for liver transplant candidates with hepatocellular carcinoma and marginal hepatic reserve. J. Hepatocell. Carcinoma 2019, 6, 93-103. [CrossRef]

109. Kirihara, M.; Nagashima, M.; Higuchi, K.; Tahira, H.; Tajima, M. A case report of unresectable hepatocellular carcinoma (HCC) with portal vein tumor thrombus responding to DSM-TACE (degradable starch microspheres-transcatheter arterial chemoembolization). Gan kagaku ryoho. Cancer Chemother. 2010, 37, 2705-2707.

110. Asahara, S.; Ikari, T.; Kamei, A.; Sato, E.; Takano, K.; Fujita, N.; Shimizu, M.; Fujita, R. A case of diffuse type of hepatocellular carcinoma with tumor thrombosis of inferior vena cava (Vv3) and main trunk of portal vein (Vp4), showing marked response to transcatheter arterial chemoembolization with degradable starch microspheres (DSM-TACE). Nihon Shokakibyo Gakkai Zasshi 2004, 101, 1332-1339.

111. Shitara, K.; Fukunari, H.; Fujimori, Y.; Sho, O.; Hayashi, T. A case of diffuse invasive hepatocellular carcinoma associated with thrombosis of the main trunk of the portal vein in which hepatic transcatheter arterial chemoembolization concomitant to the use of degradable starch microspheres (DSM-TACE) was very effective. Gan kagaku ryoho. Cancer Chemother. 2006, 33, 1807-1810.

112. Minici, R.; Ammendola, M.; Manti, F.; Siciliano, M.A.; Giglio, E.; Minici, M.; Melina, M.; Currò, G.; Laganà, D. Safety and Efficacy of Degradable Starch Microspheres Transcatheter Arterial Chemoembolization as a Bridging Therapy in Patients with Early Stage Hepatocellular Carcinoma and Child-Pugh Stage B Eligible for Liver Transplant. Front. Pharmacol. 2021, 12, 462. [CrossRef]

113. Minici, R.; Ammendola, M.; Manti, F.; Siciliano, M.A.; Minici, M.; Komaei, I.; Currò, G.; Laganà, D. Safety and Efficacy of Degradable Starch Microspheres Transcatheter Arterial Chemoembolization (DSM-TACE) in the Downstaging of IntermediateStage Hepatocellular Carcinoma (HCC) in Patients With a Child-Pugh Score of 8-9. Front. Pharmacol. 2021, 12, 634087. [CrossRef]

114. Salem, R.; Gordon, A.C.; Mouli, S.; Hickey, R.; Kallini, J.; Gabr, A.; Mulcahy, M.F.; Baker, T.; Abecassis, M.; Miller, F.H.; et al. Y90 Radioembolization Significantly Prolongs Time to Progression Compared With Chemoembolization in Patients With Hepatocellular Carcinoma. Gastroenterology 2016, 151, 1155-1163. [CrossRef]

115. Fujiki, M.; Aucejo, F.; Choi, M.; Kim, R. Neo-adjuvant therapy for hepatocellular carcinoma before liver transplantation: Where do we stand? World J. Gastroenterol. 2014, 20, 5308-5319. [CrossRef]

116. Gabr, A.; Kulik, L.; Mouli, S.; Riaz, A.; Ali, R.; Desai, K.; Mora, R.A.; Ganger, D.; Maddur, H.; Flamm, S.; et al. Liver Transplantation Following Yttrium-90 Radioembolization: 15-Year Experience in 207-Patient Cohort. Hepatology. 2021, 73, 998-1010. [CrossRef]

117. Wang, Y.-F.; Dai, Y.-H.; Lin, C.-S.; Chang, H.-C.; Shen, P.-C.; Yang, J.-F.; Hsiang, C.-W.; Lo, C.-H.; Huang, W.-Y. Clinical outcome and pathologic correlation of stereotactic body radiation therapy as a bridge to transplantation for advanced hepatocellular carcinoma: A case series. Radiat. Oncol. 2021, 16, 15. [CrossRef]

118. Guarneri, A.; Franco, P.; Romagnoli, R.; Trino, E.; Mirabella, S.; Molinaro, L.; Rizza, G.; Filippi, A.R.; Carucci, P.; Salizzoni, M.; et al. Stereotactic ablative radiation therapy prior to liver transplantation in hepatocellular carcinoma. Radiol. Med. 2016, 121, 873-881. [CrossRef]

119. Wong, T.C.; Lee, V.H.; Law, A.L.; Pang, H.H.; Lam, K.; Lau, V.; Cui, T.Y.; Fong, A.S.; Lee, S.W.; Wong, E.C.; et al. Prospective Study of Stereotactic Body Radiation Therapy for Hepatocellular Carcinoma on Waitlist for Liver Transplant. Hepatology 2021, 74, 2580-2594. [CrossRef]

120. Hoffmann, K.; Ganten, T.; Gotthardtp, D.; Radeleff, B.; Settmacher, U.; Kollmar, O.; Nadalin, S.; Karapanagiotou-Schenkel, I.; Von Kalle, C.; Jäger, D.; et al. Impact of neo-adjuvant Sorafenib treatment on liver transplantation in HCC patients-A prospective, randomized, double-blind, phase III trial. BMC Cancer 2015, 15, 392. [CrossRef]

121. Golse, N.; Radenne, S.; Rode, A.; Ducerf, C.; Mabrut, J.-Y.; Merle, P. Liver Transplantation After Neoadjuvant Sorafenib Therapy: Preliminary Experience and Literature Review. Exp. Clin. Transplant. 2018, 16, 227-236.

122. Llovet, J.M.; Ricci, S.; Mazzaferro, V.; Hilgard, P.; Gane, E.; Blanc, J.F.; de Oliveira, A.C.; Santoro, A.; Raoul, J.L.; Forner, A.; et al Sorafenib in advanced hepatocellular carcinoma. N. Engl. J. Med. 2008, 359, 378-390. [CrossRef] [PubMed] 
123. Cheng, A.-L.; Kang, Y.-K.; Chen, Z.; Tsao, C.-J.; Qin, S.; Kim, J.S.; Luo, R.; Feng, J.; Ye, S.; Yang, T.-S.; et al. Efficacy and safety of sorafenib in patients in the Asia-Pacific region with advanced hepatocellular carcinoma: A phase III randomised, double-blind, placebo-controlled trial. Lancet Oncol. 2008, 10, 25-34. [CrossRef]

124. Suzuki, H.; Mori, M.; Kawaguchi, C.; Adachi, M.; Miura, S.; Ishii, H. Serum vascular endothelial growth factor in the course of transcatheter arterial embolization of hepatocellular carcinoma. Int. J. Oncol. 1999, 14, 1087-1177. [CrossRef] [PubMed]

125. Facciorusso, A.; Tartaglia, N.; Villani, R.; Serviddio, G.; Ramai, D.; Mohan, B.P.; Chandan, S.; Aziz, M.A.A.E.; Evangelista, J.; Cotsoglou, C.; et al. Lenvatinib versus sorafenib as first-line therapy of advanced hepatocellular carcinoma: A systematic review and meta-analysis. Am. J. Transl. Res. 2021, 13, 2379-2387. [PubMed]

126. Facciorusso, A.; El Aziz, M.A.A.; Sacco, R. Efficacy of Regorafenib in Hepatocellular Carcinoma Patients: A Systematic Review and Meta-Analysis. Cancers 2019, 12, 36. [CrossRef] [PubMed]

127. Liu, Z.; Fu, Z.; Li, G.; Lin, D. Downstaging of Recurrent Advanced Hepatocellular Carcinoma After Lenvatinib Treatment: Opportunities or Pitfalls? A Case Report. OncoTargets Ther. 2020, 13, 10267-10273. [CrossRef] [PubMed]

128. Mazzaferro, V. Squaring the circle of selection and allocation in liver transplantation for HCC: An adaptive approach. Hepatology 2015, 63, 1707-1717. [CrossRef]

129. Cillo, U.; Burra, P.; Mazzaferro, V.; Belli, L.; Pinna, A.D.; Spada, M.; Nanni Costa, A.; Toniutto, P.; I-BELT (Italian Board of Experts in the Field of Liver Transplantation). A Multistep, Consensus-Based Approach to Organ Allocation in Liver Transplantation: Toward a "Blended Principle Model". Am. J. Transplant. 2015, 15, 2552-2561. [CrossRef]

130. Di Sandro, S.; Bagnardi, V.; Cucchetti, A.; Lauterio, A.; De Carlis, R.; Benuzzi, L.; Danieli, M.; Botta, F.; Centonze, L.; Najjar, M.; et al. From a Philosophical Framework to a Valid Prognostic Staging System of the New "Comprehensive Assessment" for Transplantable Hepatocellular Carcinoma. Cancers 2019, 11, 741. [CrossRef] 